\title{
QUALIDADE FÍSICO-QUÍMICA, EXTRAÇÃO E EXPORTAÇÃO DE NUTRIENTES DA CULTIVAR CABERNET SAUVIGNON SOBRE DOIS PORTA-ENXERTOS
}

Physico-Chemical Quality, Extraction and Export of Nutrients of Cabernet Sauvignon Cultivar on Two Rootstocks

\author{
Jean Carlos Bettoni ${ }^{1}$ \\ João Peterson Pereira Gardin² \\ Rafael Lizandro Schumacher ${ }^{3}$ \\ Oclair Teles Rodrigues ${ }^{4}$ \\ Juliana Aparecida Souza ${ }^{5}$ \\ Recebido em: 17 abr. 2013 \\ Aceito em: 22 mai. 2013
}

\section{RESUMO}

Objetivou-se avaliar o dessecamento da ráquis, a produtividade, extração e exportação de nutrientes da cultivar Cabernet Sauvignon sobre dois portaenxertos, 'Paulsen' 1103 e 'VR 043-43'. O experimento foi conduzido em um parreiral da Estação Experimental de Videira, Videira-SC, na safra 2009-2010, com a sustentação em latada seguindo espaçamento de $1,5 \mathrm{X}$ 3,0 metros, totalizando 2.222 plantas. ha ${ }^{-1}$. O delineamento experimental foi inteiramente casualizado com dois tratamentos (porta-enxertos) e 15 repetições. Determinaram-se a porcentagem de dessecamento da ráquis, os componentes de produtividade, qualidade, a extração e a exportação de

\footnotetext{
1 Engenheiro Agrônomo, Mestrando em Produção Vegetal - Udesc-Cav, e-mail: jcbettoni@gmail.com.

Engenheiro Agrônomo, Doutor em Fisiologia Vegetal, Professor de Bioquímica e Fisiologia Vegetal, Unoesc, Videira-SC, e-mail: joão.gardin@unoesc.edu.br.

${ }^{3}$ Engenheiro Agrônomo, Mestre em Ciência e Tecnologia Agroindustrial, Doutorando em Enologia, Universidad de Castilla La-Mancha, Ciudad Real, Espanha, e-mail: rlschumacher@gmail.com.

${ }^{4}$ Engenheiro Agrônomo, Coordenador e professor do curso técnico em agroindústria e professor do curso técnico em agronegócio na E.E.G Estanislau Schuman de Bela Vista do Toldo - SC , e-mail: oclairteles@gmail.com.

${ }^{5}$ Acadêmica do curso de Ciências Biológicas da Universidade Alto Vale do Rio do Peixe (Uniarp), e-mail: ja.souza1988@hotmail.com.
} 
nutrientes $\left(\mathrm{Kg}^{\mathrm{h}} \mathrm{ha}^{-1}\right)$. Os dados foram submetidos à análise de variância e as médias comparadas pelo teste $\mathrm{T}$ de Student a $5 \%$ de probabilidade de erro. Os resultados obtidos permitiram concluir que dentre os portaenxertos utilizados, para as condições de Videira-SC, o 'VR 043-43' é mais produtivo que o 'Paulsen 1103', apresenta também níveis de acidez superiores e maior extração de P. O porta-enxerto Paulsen 1103 apresenta, como característica indesejável, maior porcentagem de dessecamento de ráquis. Dentre os macronutrientes extraídos pela planta, o único que apresenta diferença estatística entre os porta-enxertos é o fósforo, sendo maior quantidade é extraída quando utilizado o portaenxerto VR 043-43.

Palavras-chaves: Viticultura. Distúrbio fisiológico. Vitis vinífera.

\section{ABSTRACT}

The objective was to evaluate the drying of rachis, productivity, nutrient extraction and export of cultivar Cabernet Sauvignon on two rootstocks, 'Paulsen' 1103 and 'VR 043-43'. The experiment was conducted in a vineyard at the Experimental Station Videira, Videira-SC, in the 2009-2010 season, with the support of trellis following spacing of $1.5 \times 3.0$ meters, totaling 2,222 plants.ha-1. The experimental design was completely randomized design with two treatments (rootstocks) and 15 repetitions. We determined the percentage of desiccation, the components of productivity, quality, extraction and export of nutrients (kg ha-1). Data were subjected to analysis of variance and means compared by Student $t$ test at $5 \%$ probability. The results showed that among the rootstocks used for the conditions of Videira-SC, the 'VR 043-43' is more productive than the 'Paulsen 1103' were also higher levels of acidity. The rootstock 1103 Paulsen presented as undesirable feature the highest percentage of desiccation of rachis. Among the nutrients extracted by the plant, the only one with significant differences between rootstocks is the match, while much is extracted when using the RV 043-43 rootstock.

Keywords: Viticulture. Physiological disorder. Vitis vinifera.

\section{INTRODUÇÃO}

A cultivar Cabernet Sauvignon, originária da região de Bordeaux, na França, é considerada uma das mais nobres viníferas e difundida atualmente na maior parte dos países vitivinícolas. A uva apresenta 
características peculiares, produzindo vinhos varietais de ótima qualidade. Quando propagada sobre porta-enxertos vigorosos, apresenta altos níveis de dessecamento de cacho, causado principalmente pelo atraso da maturação das uvas. Por outro lado, como ponto positivo essa cultivar, pode-se ressaltar à elevada resistência a podridão do cacho (Fregoni, 1998; Manfroi, 1997).

Segundo Giovannini (1999), alguns porta-enxertos como 101-14 $\operatorname{Mgt}(V$. riparia $\times$ V. rupestris), Paulsen 1103 (V. berlandieri $\times$ V. rupestris), 420A ( $V$. berlandieri x V. riparia) e Riparia Gloire (V. riparia), imprimem médio vigor à planta com uma produção limitada e boa maturação das bagas de uva. No entanto, outros porta-enxertos como o VR 043-43 (V. vinífera $\times$ V. rotundifolia) e 039-16 ( $V$. vinífera $\times$ V rotundifolia) geram copas mais vigorosas, que retardam a época de colheita, ocasionando maior exposição das uvas aos fatores climáticos. Como característica desejável, apresentam tolerância à pérola da terra (Eurhizococcus brasiliensis), considerada atualmente a principal praga da viticultura brasileira (Pommer et al., 2003).

A variação na qualidade da uva também está intimamente ligada às condições ambientais reinantes e o manejo utilizado. Esses fatores, quando não favoráveis ou executados de maneira errônea, podem causar distúrbios fisiológicos nos cachos, acarretando o murchamento das bagas e consequente dessecamento da ráquis (Terra, 2003). Cultivares como Cabernet Sauvignon, Merlot e Cabernet Franc possuem certa suscetibilidade a esses distúrbios (Pommer et al., 2003).

O manejo nutricional deve ser feito analisando a interação entre o solo, o porta-enxerto e a cultivar produtora (Mielle et al., 2009), sendo essa, uma prática comum realizada de forma empírica pelos produtores. É necessário conhecer a quantidade de nutrientes utilizados pela planta para 
o desenvolvimento vegetativo e reprodutivo, levando em conta a quantidade desse nutrientes exportados em decorrência da colheita. Desse modo, torna-se necessário a utilização de adubações equilibradas em função da quantidade de nutrientes exportados (Albuquerque et al., 2005).

Objetivou-se, neste trabalho, avaliar incidência de dessecamento de ráquis, a produtividade, qualidade, extração e exportação de nutrientes pelos cachos da cultivar Cabernet Sauvignon enxertada sobre dois portaenxertos.

\section{MATERIAL E MÉTODOS}

O experimento foi instalado em março de 2010, na Estação Experimental da Epagri, no município de Videira, no Alto Vale do Rio do Peixe, com altitude de $750 \mathrm{~m}$. Conforme a classificação de Koppen, a estação experimental está sob domínio climático Cfb - Temperado (mesotérmico úmido e verão ameno) com temperaturas médias entre $16^{\circ} \mathrm{C}$ a $17^{\circ} \mathrm{C}$ e precipitação média anual de 1300 a $1500 \mathrm{~mm}$. O solo foi classificado como Nitossolo Vermelho Distrófico.

O delineamento experimental utilizado foi inteiramente casualizado, sendo dois tratamento representados pelos porta-enxerto e 15 repetições. As variáveis analisadas foram: porcentagem de cachos com dessecamento de ráquis, produtividade $\left(\mathrm{Kg}_{\mathrm{h}} \mathrm{ha}^{-1}\right)$, número de cachos por planta, peso e volume médio de 100 bagas, peso médio de cacho, extração de nutrientes pela planta, exportação de nutrientes pelos cachos e qualidade da uva (acidez, pH e sólidos solúveis totais).

Utilizaram-se plantas com cultivar copa Cabernet Sauvignon com oito anos de idade, cultivadas sobre o sistema latada, seguindo o 
espaçamento $1,5 \times 3,0$ metros, totalizando 2.222 plantas.ha $^{-1}$.

Previamente, fez-se a análise de solo do pomar, na camada de 0 a $20 \mathrm{~cm}$ de profundidade (Tabela 1), verificado a necessidade de calagem e adubação, realizou-se calagem em superfície na dose de três toneladas.ha $^{-1}$ e correção de nutrientes em área total, interpretação conforme Sociedade Brasileira de Ciência do Solo (2004).

Tabela 1. Resultados das análises de solo. Estação Experimental de Videira, SC, 2009.

\begin{tabular}{|c|c|c|c|c|c|c|c|c|c|c|}
\hline $\begin{array}{l}\% \\
\text { Argila }\end{array}$ & $\begin{array}{l}\text { pH } \\
\text { Água } \\
1: 1\end{array}$ & $\begin{array}{l}\text { Índice } \\
\text { SMP }\end{array}$ & $P$ & $\mathrm{~K}$ & $\begin{array}{l}\text { M.O. } \\
\%\end{array}$ & $\mathrm{Al}$ & $\mathrm{Ca}+\mathrm{Mg}$ & $\mathrm{H}+\mathrm{Al}$ & $\begin{array}{l}\mathrm{CTC} \\
\mathrm{pH} \\
7,0\end{array}$ & $\begin{array}{l}\text { \% } \\
\text { Saturação } \\
\text { CTC } \\
\text { Bases Al }\end{array}$ \\
\hline 65 & 5,2 & 5,7 & 3,9 & 261 & 3,8 & 0,9 & 10,9 & 6,7 & 18,2 & $62 \quad 7,1$ \\
\hline
\end{tabular}

Os dados acima refletem a média de 32 amostras. $\mathrm{O} P$ e o $\mathrm{K}$ são dados em $\mathrm{mg} / \mathrm{dm}^{-3}$, enquanto que o $\mathrm{Al}$, o $\mathrm{Ca}+\mathrm{Mg}$, o $\mathrm{H}+\mathrm{Al}$ e a CTC em $\mathrm{pH}$ 7,0 são dados em $\mathrm{cmolc} / \mathrm{dm}^{-3}$.

A porcentagem de dessecamento da ráquis foi obtida pela observação da presença do distúrbio nos cachos e dividida pelo número de cachos. A estimativa de produtividade se deu através do produto do peso médio de cachos pelo número de cachos. O volume de 100 bagas foi medido colocando as bagas em uma proveta e completando com água. $\mathrm{O}$ volume usado de água servia para medir o de bagas. A análise de exportação de nutrientes foi obtida através da metodologia descrita por Tedesco et al., (1995). Para a análise de extração de nutrientes, coletaram-se 50 pecíolos de folhas opostas ao primeiro cacho do ramo para cada repetição.

Os dados foram submetidos à análise de variância e as médias dos tratamentos foram comparadas pelo teste de T de Student a $5 \%$ de probabilidade de erro. 


\section{RESULTADOS E DISCUSSÃO}

A porcentagem de dessecamento de ráquis foi maior no portaenxerto 'Paulsen 1103' quando comparada ao VR 043-43 (Tabela 2). Mielle et al., (2009) verificaram o efeito dos porta-enxertos no teor de nutrientes na videira e citam que o dessecamento da ráquis é ocasionado quando há uma relação desequilibrada entre $\mathrm{K}$ e $\mathrm{Mg}$, principalmente elevado teor de $\mathrm{K}$ e baixo de $\mathrm{Mg}$.

Apesar dos teores de $\mathrm{Mg}$ da grande maioria dos solos brasileiros serem baixos, esse elemento não tem sido problema sério para a videira, pois, como para o cálcio, a utilização de calcário dolomítico para aumentar o pH do solo também aumenta o teor de Mg (Melo, 2003). Tem-se observado que o dessecamento da ráquis ocorre mais frequentemente em anos em que o período de maturação dos frutos é bastante chuvoso e o solo apresenta-se com alto teor de potássio e baixo de magnésio (Melo, 2003). Essas condições de clima e níveis de nutrientes ocorreram no experimento em questão (Tabelas 1 e 3 ). Os teores de magnésio considerados normais para a videira variam de 0,25 a $0,50 \%$, sendo que as plantas retiram cerca de $1 \mathrm{~kg}$ de $\mathrm{MgO}$ para produzir $1000 \mathrm{~kg}$ de frutos (Melo, 2003).

Ainda na tabela 2 apresentaram-se os valores de produtividade e qualidade dos cachos da cultivar Cabernet Sauvignon. Para a variável produtividade, constatou-se diferença significativa entre os tratamentos, sendo que o porta-enxerto 'VR 043-43' foi superior ao 'Paulsen1103', com um incremento de $7009 \mathrm{Kg} \cdot \mathrm{ha}^{-1}$. De acordo com Botton, et al. (2008), durante avaliação por cinco anos, estudando a produtividade da cultivar sobre os porta-enxertos VR 043-43, R99, Paulsen 1103 e 101-14Mgt, constatou-se que em todos os anos o porta-enxerto VR 43-43 teve uma produção estável, enquanto que nos outros houve um declínio na 
produção.

Tabela 2. Produtividade e qualidade dos cachos da cultivar Cabernet Sauvignon na Estação Experimental de Videira - Santa Catarina, no ano de 2010.

\begin{tabular}{|c|c|c|c|c|c|c|}
\hline Variáveis & $\begin{array}{l}\text { VR } \\
043-43\end{array}$ & $\begin{array}{l}\text { Paulsen } \\
1103\end{array}$ & t-valor & GL & $\mathrm{p}$ & $\mathrm{N}$ \\
\hline Porcentagem de dessecamento & 6,82 & 11,96 & $-2,45758$ & 28 & $\begin{array}{l}0,02044 \\
1\end{array}$ & 15 \\
\hline Produtividade $\left(\mathrm{kg} \cdot \mathrm{ha}^{-1}\right)$ & 15807 & 8798 & 5,88284 & 28 & $\begin{array}{l}0,00000 \\
3\end{array}$ & 15 \\
\hline № de cachos por planta & 46,13 & 31,4 & 4,04841 & 28 & $\begin{array}{l}0,00036 \\
9\end{array}$ & 15 \\
\hline Peso médio de cacho (gramas) & 154,2 & 126,1 & $-2,11655$ & 28 & $\begin{array}{l}0,05587 \\
7\end{array}$ & 15 \\
\hline $\begin{array}{l}\text { Peso médio de } 100 \text { bagas } \\
\text { (gramas) }\end{array}$ & 158,5 & 169,7 & 2,06016 & 28 & $\begin{array}{l}0,06175 \\
3\end{array}$ & 15 \\
\hline Volume médio de 100 bagas (mL) & 147,1 & 158,3 & 1,65468 & 28 & $\begin{array}{l}0,12388 \\
8\end{array}$ & 15 \\
\hline Acidez (gramas/L de ác. tartárico) & 9,7693 & 8,5618 & 3,13081 & 12 & $\begin{array}{l}0,00867 \\
9\end{array}$ & 7 \\
\hline Sólidos solúveis totais ( ${ }^{\circ}$ Brix) & 17,725 & 18,569 & $-1,60471$ & 12 & $\begin{array}{l}0,13453 \\
6\end{array}$ & 7 \\
\hline $\mathrm{Ph}$ & 5,5114 & 3,478 & 1,05978 & 12 & $\begin{array}{l}0,31010 \\
9\end{array}$ & 7 \\
\hline
\end{tabular}

$\mathrm{GL}=$ graus de liberdade; $\mathrm{p}=$ probabilidade a $5 \% ; \mathrm{N}=$ número de observações por portaenxerto.

Os componentes do rendimento que contribuíram para a maior produtividade do porta-enxerto VR 043-43 foram o número de cachos por planta e o peso médio de cachos (Tabela 2). Brighenti, et al., (2008) estudaram o comportamento da Cabernet Sauvignon sobre os portaenxertos Couderc 3309, 101-14 Mgt e Paulsen 1103 e verificaram que o primeiro apresentou valores mais elevados para peso de cacho e de 50 bagas.

Para as variáveis peso médio e volume médio de 100 bagas (Tabela 2), não houve diferença significativa entre os tratamentos, no entanto, verificou-se uma tendência de o porta-enxerto Paulsen 1103 ser superior ao VR 043-43 para o peso médio de 100 bagas. Esse resultado pode ser explicado pelo fato de o porta-enxerto VR 043-43 proporcionar maior desuniformidade de volume de bagas quando comparado com 0 
'Paulsen 1103', verificado por Gardin et al., (2010) trabalhando com a cultivar copa Niágara Rosada sob cobertura plástica.

Dentre os fatores que determinam a qualidade da uva, o único que apresentou diferença estatística foi a acidez, sendo mais elevada para o 'VR 043-43'. Deve-se ao fato desse ser mais vigoroso, induzindo maior vigor à copa e prolongando o período de crescimento vegetativo, retardando o acúmulo de açúcar nos frutos.Por outro lado, o 'Paulsen 1103',por ser de vigor médio, induz o amadurecimento precoce (Sampaio, 2007).

Para a análise de extração de nutrientes (Tabela 3, o porta-enxerto VR 43-43 diferenciou-se significativamente do 'Paulsen 1103' para o nutriente $P$, com 3,87469 e 2,36290 g. Kg ${ }^{-1}$ respectivamente. Os resultados obtidos para os demais nutrientes não foram significativos. Segundo Faria et al., (2004) em plantas com adequada nutrição, os teores de $P$ no pecíolo na época de floração e na fase de colheita são de 4,13 e 1,33 g.Kg ${ }^{1}$, respectivamente.

O efeito do porta-enxerto na extração de nutrientes e acúmulo nos diferentes tecidos da 'Cabernet Sauvignon' dependem de diversos fatores, destacando-se a carga genética do material vegetativo, ou seja, copa ou porta-enxerto.

Para a variável exportação de nutrientes pelo cacho (Tabela 3), constatou-se diferença estatística somente para 0 nutriente $\mathrm{K}$, com exportação de 2048 e 1829 Kg.ha-1, para o porta-enxerto 'VR 043-43' e 'Paulsen 1103', respectivamente. Em trabalho desenvolvido por Albuquerque et al,. (2005), estudando a exportação de nutrientes das cultivares Itália e Benitaka, em suas diferentes partes do fruto (semente, ráquis e polpa), constataram que $0 \mathrm{~K}$ foi o nutriente mais exportado pela ráquis e polpa e o $\mathrm{N}$ pela semente. Quando analisados as quantidades de 
nutrientes exportados pela cultura, tem-se, como ordem decrescente $\mathrm{K}, \mathrm{N}$, $P$, para ambos os porta-enxertos, resultados semelhantes aos encontrados por Dechen (1979), obedecendo à mesma sequência. Considera-se que a absorção de $\mathrm{K}$ pelas células das bagas das uvas seja mais rápida do que para pecíolos e folhas. Além disso, esse mineral participa do processo de translocação de açúcares até os grãos, acontecendo em maior intensidade ao período final da maturação (Smart et al.,1985).

Um aspecto verificado por Fogaça et al., (2007) é que, em duas safras da cultivar Cabernet Sauvignon, nos estádios que compreendem entre o início da coloração das bagas até a colheita, houve aumento no $\mathrm{pH}$ e na quantidade de $\mathrm{K}$ no fruto. Assim, analisando os dados de $\mathrm{pH}$ (Tabela 2) e quantidade de $\mathrm{K}$ exportado (Tabela 3 ), verifica-se que o porta-enxerto que teve exportação de $\mathrm{K}$ superior (VR 043-43) também apresentou uma tendência do $\mathrm{pH}$ ser maior na hora da colheita.

Tabela 3. Extração de nutrientes pela planta e exportação de nutrientes pelo cacho em decorrência da colheita na cultivar Cabernet Sauvignon na Estação Experimental de Videira - Santa Catarina, no ano de 2010. 


\begin{tabular}{|c|c|c|c|c|c|c|}
\hline Variáveis & $\begin{array}{l}\text { VR } \\
043-43 \\
\end{array}$ & $\begin{array}{l}\text { Paulsen } \\
1103\end{array}$ & t-valor & GL & $\mathrm{p}$ & $\mathrm{N}$ \\
\hline & \multicolumn{6}{|c|}{ Extração $\left(\mathrm{g} \cdot \mathrm{Kg}^{-1}\right)$} \\
\hline Nitrogênio (N) & 7,82857 & 8,88571 & 1,25202 & 12 & $\begin{array}{l}0,23441 \\
6\end{array}$ & 7 \\
\hline Fósforo (P) & 3,87469 & 2,36290 & $-2,76586$ & 12 & $\begin{array}{l}0,01709 \\
2\end{array}$ & 7 \\
\hline Potássio (K) & 45,16914 & $\begin{array}{l}49,4560 \\
0\end{array}$ & 1,20583 & 12 & $\begin{array}{l}0,25112 \\
2\end{array}$ & 7 \\
\hline Cálcio (Ca) & 25,67429 & 26,3600 & 0,41336 & 12 & $\begin{array}{l}0,68663 \\
4\end{array}$ & 7 \\
\hline Magnésio (Mg) & 9,10857 & 9,08429 & $-0,10467$ & 12 & $\begin{array}{l}0,91836 \\
4\end{array}$ & 7 \\
\hline $\mathrm{N} / \mathrm{Ca}$ & 0,3394 & 0,3075 & 0,93970 & 12 & $\begin{array}{l}0,36590 \\
0\end{array}$ & 7 \\
\hline $\mathrm{K} / \mathrm{Ca}$ & 1,8052 & 1,8973 & 0,45347 & 12 & $\begin{array}{l}0,65830 \\
5\end{array}$ & 7 \\
\hline $\mathrm{K} / \mathrm{Mg}$ & 4,9847 & 5,4502 & 1,11815 & 12 & $\begin{array}{l}0,28539 \\
0\end{array}$ & 7 \\
\hline $\mathrm{Ca} / \mathrm{Mg}$ & 2,8180 & 2,8951 & 0,53084 & 12 & $\begin{array}{l}0,60521 \\
4\end{array}$ & 7 \\
\hline \multirow[t]{2}{*}{$\mathrm{K}+\mathrm{Mg} / \mathrm{Ca}$} & 2,1639 & 2,2447 & 0,36961 & 12 & $\begin{array}{l}0,71811 \\
3\end{array}$ & 7 \\
\hline & \multicolumn{6}{|c|}{ Exportação (Kg.ha $\left.{ }^{-1}\right)$} \\
\hline Nitrogênio (N) & 1571,429 & 1547 & $-0,24767$ & 12 & $\begin{array}{l}0,80857 \\
3\end{array}$ & 7 \\
\hline Fósforo $(\mathrm{P})$ & 309,143 & 307,286 & $-0,06642$ & 12 & $\begin{array}{l}0,94813 \\
6\end{array}$ & 7 \\
\hline Potássio (K) & 2048,714 & $\begin{array}{l}1829,71 \\
4\end{array}$ & $-2,93128$ & 12 & $\begin{array}{l}0,01257 \\
4\end{array}$ & 7 \\
\hline Cálcio (Ca) & 175 & 166,714 & $-0,38162$ & 12 & $\begin{array}{l}0,70941 \\
7\end{array}$ & 7 \\
\hline Magnésio (Mg) & 113,571 & 93,571 & $-1,74877$ & 12 & $\begin{array}{l}0,10583 \\
9\end{array}$ & 7 \\
\hline $\mathrm{N} / \mathrm{Ca}$ & 9,455 & 9,371 & $-0,09753$ & 12 & $\begin{array}{l}0,92391 \\
7\end{array}$ & 7 \\
\hline $\mathrm{K} / \mathrm{Ca}$ & 12,569 & 11,174 & 0,94366 & 12 & $\begin{array}{l}0,36395 \\
7\end{array}$ & 7 \\
\hline $\mathrm{K} / \mathrm{Mg}$ & 18,525 & 19,962 & 1,00027 & 12 & $\begin{array}{l}0,33692 \\
5\end{array}$ & 7 \\
\hline $\mathrm{Ca} / \mathrm{Mg}$ & 1,832 & 1,550 & 1,34604 & 12 & $\begin{array}{l}0,20316 \\
7\end{array}$ & 7 \\
\hline $\mathrm{K}+\mathrm{Mg} / \mathrm{Ca}$ & 13,249 & 11,743 & 0,97496 & 12 & $\begin{array}{l}0,34882 \\
7\end{array}$ & 7 \\
\hline
\end{tabular}

GL= graus de liberdade; $\mathbf{p =}$ probabilidade a $5 \% ; \mathbf{N}=$ número de observações por portaenxerto. 


\section{CONCLUSÕES}

O porta enxerto VR-043-43 aumentou a acidez, a produtividade e a quantidade extraída de $\mathrm{P}$ em relação ao Paulsen 1103.

O porta-enxerto Paulsen 1103 apresenta maior porcentagem de dessecamento de ráquis quando comparado ao VR 043-43.

O potássio é o nutriente mais exportado pela cultura, sendo maiores índices apresentados quando utilizado o porta-enxerto VR 043-43.

\section{REFERÊNCIAS}

ALBUQUERQUE, T.C.S.; ALBUQUERQUE NETO, A.A.R.; DEON, M.D. Exportação de nutrientes pelas videiras cvs. Italia e Benitaka cultivadas no Vale do Rio São Francisco. In: X Congresso Brasileiro de Fisiologia Vegetal e XII Congresso Latino-americano de Fisiologia Vegetal, Recife. Anais, 2005.

BOTTON, M. et al. Manejo de pragas na cultura da videira. Embrapa Uva e Vinho. Disponível em:

<http://www.cnpuv.embrapa.br/publica/sprod/viticultura/perola.html>. Acessado em: 27 jul. 2010.

BRIGHENTI, A.F. et al. Características físico-químicas da uva Cabernet Sauvignon sobre diferentes porta-enxertos em regiões de altitude de Santa Catarina. In: XX Congresso Brasileiro de Fruticultura, Vitória. Anais, 2008.

DECHEN A. R. Acúmulo de nutrientes pela videira (Vitis labrusca L. $\mathbf{x}$ Vitis vinifera L.) cv. 'Niagara Rosada', durante um ciclo vegetativo. Dissertação de Mestrado. USP-ESALQ, Piracicaba, 1979. 133 p.

FARIA, C.M.B.; SILVA, D.J.; PEREIRA, J.R. Avaliação nutricional da videira no Submédio São Francisco. Boletim de Pesquisa e Desenvolvimento, Petrolina, n. 61, 2004. 20 p.

FOGAÇA, A.O.; DAUDT, C.E.; DORNELES, F. O Potássio em uvas II Análise peciolar e sua correlação com o teor de potássio em uvas viníferas. Ciência e Tecnologia dos Alimentos, Campinas, v. 27, n. 3, p. 597-601, 
2007.

FREGONI, M. Viticoltura di qualitá. Edizione I' Informatore Agrário, 1998. $707 p$.

GIOVANNINI, E. Produção de Uvas para Vinho, Suco e Mesa. Porto Alegre: Renascença, 1999. 364p.

GARDIN J.P.P. et al. Influência de diferentes porta-enxertos na produção e qualidade de cacho da cultivar Niágara Rosada (Vitis Labrusca L.) sob cobertura plástica em cultivo orgânico. In: XXI Congresso Brasileiro de Fruticultura, Natal, Anais, 2010.

MANFROI, V. Efeito de épocas de desfolha e de colheita sobre a maturação e qualidade da uva e do vinho 'Cabernet Sauvignon'. Dissertação de Mestrado (Mestre em fitotecnia) - Faculdade de Agronomia, Universidade Federal do Rio Grande do Sul, 1997. 138p.

MELO, W.G. Uvas viníferas para processamento em regiões de clima temperado. Sistema de produção 3, Embrapa Uva e Vinho, 2003.

Disponível em:

http://sistemasdeproducao.cnptia.embrapa.br/FontesHTML/Uva/UvasVinife rasRegioesClimaTemperado/solo.htm. Acesso em: 23 set. 2010.

MIELE, A,; RIZZON, L.A.; GIOVANNINI, E. Efeito do porta-enxerto no teor de nutrientes em tecidos da videira "Cabernet Sauvignon". Revista Brasileira de Fruticultura, v. 31, p. 1141-1149, 2009.

POMMER, C.V. Uva: Tecnologia de produção, pós-colheita. Cinco Continentes, 2003. 634 p.

SBCS - Sociedade Brasileira de Ciência do Solo. Manual de adubação e calagem para os estados do Rio Grande do Sul e de Santa Catarina. 10. ed. Porto Alegre, Comissão de Química e Fertilidade do Solo, 2004. 394p.

SAMPAIO, T.L.B. Using Rootstocks to Manipulate Vine Physiological Performance and Mediate Changes in Fruit and Wine Composition. Oregon State University. Oregon, EUA, 2007. 240p.

SMART, R.E. et al. Canopy microclimate modification for the cultivar Shiraz. I. Definition of canopy microclimate. Vitis, v. 24, p. 17-31, 1985.

TEDESCO, M.J. et al. Análise de solo plantas e outros materiais. 2. ed. 
Porto Alegre: Universidade Federal do Rio Grande do Sul, 1995. 174p.

TERRA, M,M, Nutrição, calagem e adubação. In: POMMER, Celso

Valdevino (edit.). Uva: Tecnologia de produção, pós-colheita, mercado. Porto Alegre: Cinco Continentes, 2003. p. 405-634. 